\title{
METABOLITHOTROPIC ASPECTS OF CARDIOPROTECTIVE ACTION OF NEW COMBINED MEDICINE BASED ON L-ARGININE AND THIOTRIAZOLIN AT MODELING OF MYOCARDIAL INFARCTION
}

\section{KUCHERENKO LYUDMILA IVANOVNA ${ }^{1,2}$, BELENICHEV IGOR FEDOROVICH ${ }^{3}$, MAZUR IVAN ANTONOVICH ${ }^{1,2}$, KHROMYLOVA OLGA VLADIMIROVNA ${ }^{1}$}

${ }^{1}$ Department of Pharmaceutical Chemistry, Zaporozhye State Medical University, Zaporozhye, Ukraine. ${ }^{2}$ Scientific and Production Association “Farmatron", Zaporozhye, Ukraine. ${ }^{3}$ Department of Pharmacology and Medical Recipe, Zaporozhye State Medical University, Zaporozhye, Ukraine. Email: farm_chem@bigmir.net

Received: 12 May 2017, Revision and Accepted: 19 June 2017

ABSTRACT

Objectives: The actual problem of modern medicine is the development of medications in treatment of cardiovascular system diseases. Different combinations of L-arginine with thiotriazolin in acute myocardial ischemia were examined as part of study and the optimal combination has been established - 4:1, named "Argitryl." The aim is to study the antioxidant, energotropic, and nitric oxide (NO)-modulating mechanisms of the cardioprotective effects of L-arginine with thiotriazolin (4:1) (Argitryl) drug candidate compared to 4.2\% solution for injections "Tivortin" (TOV "Yuriya-Farm," Ukraine) on the model of pituitrin-isadrin infarction of myocardium in laboratory rats.

Methods: The study was conducted in accordance with Guidelines of State Expert Center of the Ministry of Health of Ukraine. All manipulations were carried out in accordance with the "European Convention for the protection of vertebrate animals used for experimental and other scientific purposes." The experiments were performed on 40 white outbred rats weighing $170-180$ g. The antioxidant activity of the drugs was assessed by reduction of biochemical marker oxidative stress and an increase in the activity of the antioxidant system of the myocardium.

Results: The study of energy metabolism has shown that the modeling of myocardial infarction leads to typical ischemic injuries - decrease in ATP, discoordination of the Krebs cycle, activation of anaerobic glycolysis in the cytosolic fraction of the heart of rats from the control group. Administration of Tivortin to animals does not lead to a significant decrease in ischemic injuries in the energy metabolism of the myocardium. The brightest antiischemic effect was observed with the appointment of "Argitryl."

Conclusion: The ascertained braking reaction of oxidative stress compared to the control group was found as a result of administration of Argitryl and Tivortin to animals with pituitrin-isadrin myocardial infarction. It was also found that the administration of Argitryl and Tivortin has a positive effect on the indices of the energy metabolism of the ischemic myocardium and leads to the normalization in conjugated NO system/renewed thiols. Argitryl significantly exceeds Tivortin on the influence of antioxidant, energy-tropic, and NO-modulating mechanisms of cardioprotective and antiischemic action on the studied indicators.

Keywords: L-arginine, Thiotriazolin, Oxidative stress, Antioxidant system, Energy metabolism, Nitroxidergic system, Myocardial infarction, Ischemia.

(c) 2017 The Authors. Published by Innovare Academic Sciences Pvt Ltd. This is an open access article under the CC BY license (http://creativecommons. org/licenses/by/4. 0/) DOI: http://dx.doi.org/10.22159/ajpcr.2017.v10i10.19895

\section{INTRODUCTION}

The diseases of the cardiovascular system rank second in the structure of disablement and mortality of the population of industrially developed countries. The development of drugs for the treatment of these pathologies is relevant objective of modern medicine $[1,2]$. L-arginine is a metabolic precursor of nitric oxide (NO), increasing its concentration in tissues, causes vasodilation and may have antiischemic and cardioprotective effects. Furthermore, L-arginine can have antiaggregation effects due to increase of NO concentration, suppressing the expression of adhesion molecules and leukocyte chemotaxis $[3,4]$. The search for ways to enhance the protective properties of L-arginine by combining with substances that can improve the energization of the ischemic myocardium, reduce the activity of oxidative stress reactions, and increase the bioavailability of NO L-arginine is of particular interest. These substances include thiotriazolin. Thiotriazolin is able to enhance the cardioprotective effect of L-arginine, potentiating its NO-mimetic and antioxidant mechanism [5]. A new combined drug, which includes L-arginine and thiotriazolin, was designed solving the relevant objective of modern medicine and pharmacy for the creation of highly effective agents for the treatment of cardiovascular pathology in the SPA "Farmatron" [6]. We have studied various combinations of L-arginine with thiotriazolin - 1:1; 2:1; 3:1; 4:1; 5:1; 6:1, and 7:1 in acute myocardial ischemia, and the optimal combination of L-arginine with thiotriazolin - 4:1, called "Argitryl" [6] was substantiated.

\section{Objective}

The aim is to study the antioxidant, energotropic, and NO-modulating mechanisms of cardioprotective effects in drug candidate - Argitryl (L-arginine with thiotriazolin [4:1]) compared to $4.2 \%$ solution for injections "Tivortin" (TOV "Yuriya-Farm," Ukraine) on the model of pituitrin-isadrin infarction of myocardium in laboratory rats.

\section{METHODS}

The study of "Argitryl" - drug candidate developed by SPA "Farmatron," Ukraine (solution for injections in vials) compared to "Tivortin" ("Yuriya-Farm," Ukraine) - 4.2\% solution for injection - was carried out in accordance with Guidelines of State Expert Center of the Ministry of Health of Ukraine [7]. All manipulations were carried out in accordance with the "European Convention for the protection of vertebrate animals used for experimental and other scientific purposes."

The experiments were performed on 40 white outbred rats weighing 170-180 g, obtained from the nursery of the state institution - Institute of Pharmacology and Toxicology of the Academy of Medical Sciences 
of Ukraine. Experimental animals were kept on a standard diet, under normal vivarium conditions [8]. Myocardial infarction (MI) was simulated by phased introduction of izadrin and pituitrin according to the following scheme: Pituitrin - $0.5 \mathrm{u} / \mathrm{kg}$ - i.p., in 20 minutes, izadrin $100 \mathrm{mg} / \mathrm{kg}$ - subcutaneously, in 6 hours, izadrin injection was repeated and after 24 hours, both agents were administrated in same doses. We have used pituitrin for injection by $\mathrm{AB}$ «Endokrininiai» (Lithuania) and izadrin by Sigma-Aldrich (Lot\#BCBB9618 (USA). This model reproduces fine-local myocardial infarction. Animals were withdrawn from the experiment within 60 minutes after the last izadrin injection under thiopental anesthesia $(40 \mathrm{mg} / \mathrm{kg})$.

The studied drugs were administered intraperitoneally 3 times during the day in parallel with the formation of myocardial in 30 minutes before the injection of pituitrin and izadrin: $200 \mathrm{mg} / \mathrm{kg}$ of Tivortin, $200 \mathrm{mg} /$ $\mathrm{kg}$ of Argitryl (L-arginine + thiotriazolin 4:1) equivalent to L-arginine. Intact and control groups were received physiological saline according to a similar scheme in equivalent volumes. There were 10 animals in each group.

The heart was washed with cold $0.15 \mathrm{M} \mathrm{KCl}\left(4^{\circ} \mathrm{C}\right), 1: 10$, and purified from fat, connective tissue, vessels were cut out, and blood clots were removed from internal cavities and washed again. Then, it was ground in liquid nitrogen to powdery condition and homogenized in 10 -fold volume of environment at $\left(2^{\circ} \mathrm{C}\right)$ containing (in mmol): Sucrose -250 , HCl-Tris-buffer -20 , EDTA- 1 (pH 7.4), and at $+4^{\circ} \mathrm{C}$ by differential centrifugation on Sigma 3-30k (Germany) refrigerated centrifuge, mitochondrial and cytosolic fractions were isolated $[9,10]$. Antioxidant activity of the drugs was evaluated by the reduction of biochemical markers of oxidative stress and increased activity of the antioxidant system of the myocardium. The markers of the oxidative modification of the protein - aldehyde phenylhydrazone (AFG) and carboxyphenylhydrazone (CPG) - were determined to assess the intensity of oxidative stress in the myocardium $[11,12]$. The state of the antioxidant system was assessed by the activity of catalase, glutathionperoxidase (GPR) $[9,10,13]$. The state of energy metabolism was determined by the level of the most significant intermediates - ATP, lactate, and malate $[10,12]$. The production, metabolism, and transport of $\mathrm{NO}$ were evaluated by the activity of NOsynthase (NOS), the content of stable metabolites of NO, and the level of total SH-groups $[10,11]$.

The catalase activity was determined in the cytosol using hydrogen peroxide and ammonium molybdate at $470 \mathrm{~nm}$ detection [10]. GPR activity was determined in the cytosol according to the tert-butyl hydroperoxide test at $540 \mathrm{~nm}$ detection [11]. Stable metabolites of NO were determined in the cytosolic fraction of the myocardium using BCM Diagnostics kits at $540 \mathrm{~nm}$ of detection, the activity of total NOS was determined in the cytosol using the NOSDetect ${ }^{\text {TM }}$ Assay Kit kits, Stratagene production, containing the NOS-N-nitroL-arginine inhibitor. The indices of oxidative modification of protein in the myocardium were determined in the cytosol by the method of Aruoma and Halliwell [11] on the interaction of oxidized amino acid residues with 2,4-dinitrophenylhydrazine and the formation of AFGs and carboxylphenylhydrazone having an absorption spectrum at $274 \mathrm{~nm}$ and $363 \mathrm{~nm}$ detection, respectively. The amount of malate was determined in the mitochondrial fraction of the myocardium by the Hohorst method by decreasing nicotinamide adenine dinucleotide (NAD) at $340 \mathrm{~nm}$ [10]. The lactate content was determined in the protein-free extract of the myocardium homogenate according to the Hohorst method by increasing the NAD at $340 \mathrm{~nm}$ [10]. The activity of NAD-dependent malate dehydrogenase (NAD-MDG) was determined in the mitochondrial fraction at $340 \mathrm{~nm}$ detection [10]. ATP was determined by thin-layer chromatography in the mitochondrial fraction $[9,10]$. The content of total SH-groups was determined in the cytosol by reaction with 5,5-dithio-bis-7-nitrobenzoic acid at $540 \mathrm{~nm}$ detection [11]. Nitrotyrosine was determined in the cytosol by ELISA solid-phase immunosorbent method, ELISA Kit (Cat. No. HK 501-02) by Hycult Biotech and expressed in $\mathrm{nmol} / \mathrm{g}$ tissue. The protein concentration was evaluated by the Bradford method. The Libra S70 PC (Biochrom Ltd. United Kingdom) spectrophotometer was used in work.

The results of the study were calculated using the standard statistical package of the licensed program "STATISTICA ${ }^{\circledR}$ for Windows 6.0 " (StatSoft Inc., No. AXXR712D833214FAN5) as well as "SPSS 16.0," "Microsoft Office Excel 2003." The normality of distribution was assessed by the Shapiro-Wilk criterion. The data are presented as mean value. The reliability of the differences between the mean values was determined by the Student's test with a normal distribution. In the case of nonnormal distribution or an analysis of ordinal variables, the U Mann-Whitney criterion was used. ANOVA was used for normal distribution or Kruskal-Wallis criterion for nonnormal distribution to compare independent variables in more than two samples. Differences $\mathrm{p}<0.05(95 \%)$ were considered statistically significant for all types of analysis.

\section{RESULTS AND ITS DISCUSSION}

The study of energy metabolism (Table 1) has showed that the modeling of myocardial infarction leads to typical ischemic injuries - decrease in ATP by $44.3 \%$, discoordination of the Krebs cycle (decrease in malate by $71.6 \%$ and decrease in MDG activity by $55 \%$ ), activation of anaerobic glycolysis (increase of lactate by 3.6 times) in the cytosolic fraction of the heart of the rats from control group. The administration of Tivortin to animals with myocardial infarction does not lead to significant decrease in ischemic injuries of the energy metabolism of the myocardium. The most striking anti-ischemic effect was observed in "Argitryl" administration.

Thus, in the myocardium of animals with MI who have been received Argitryl, a significant increase in the ATP level of $70 \%$ was observed against a background of an increase in malate by $384 \%$, which indicated normalization of the Krebs cycle and decrease in the lactate level by $58 \%$ that showed inhibition of unproductive glycolysis. An important factor in the mechanism of the energotropic action of Argitryl under conditions of myocardial ischemia was its activating effect on the compensatory malate-aspartate shunt. The malate-aspartate scapha transfer the reduced equivalents formed in the cytoplasm during glycolysis into the mitochondria in ischemia. The inhibition of the malate-aspartate shunt was observed in the modeling of myocardial infarction, which was manifested in decrease of activity of MDG (MDG by $55 \%$ ), decrease in the level of malate by $71.6 \%$. "Argitryl" intensified the activity of the malate-aspartate shunt, as evidenced by an increase in the activity of MDG and an increase of malate.

The data presented in Table 2 indicate injuries in conjugated NO systems and renewed thiols in the myocardium of experimental animals with myocardial infarction.

Thus, the deficiency of renewed thiols was registered by $50.2 \%$ against the background of oppression of glutathione reductase activity by $48.6 \%$, the decrease in NOS activity by $53 \%$, and the decrease in NO formation (decrease in stable metabolites of NO by 63\%) and increase in level of the marker of nitrosating stress - nitrotyrosine by 7.4 times in myocardium of the control group. The administration of Tivortin and Argitryl to animals with MI had a positive effect on the indicators of conjugate NO system/renewed thiols. For example, a significant increase in NOS activity by $53 \%$ and $65 \%$ against the background of an increase in NO production (an increase of stable metabolites of NO by $105 \%$ and $159 \%$ ) and decrease in nitrotyrosine by $35 \%$ and $81 \%$ in the myocardium of animals which have been received Tivortin and Argitryl. In parallel, an increase of renewed thiols by $25 \%$ and $86.4 \%$ was observed and increase of GH activity by $27 \%$ and $121.8 \%$ in the myocardium of these groups of animals. Based on the obtained results, we can conclude that Argitryl unlike Tivortin not only intensifies NO synthesis but also increases its bioavailability, preventing its formation into a cytotoxic form - peroxynitrite (as evidenced by decrease in these nitrotirozine groups). Argitryl has a direct stimulating effect on the activity of NOS and the level of L-arginine, i.e., increases the production 
Table 1: Indicators of energy metabolism in the cytosolic fraction of the heart of animals

\begin{tabular}{llll}
\hline Studied indicators & Intact & MI (control) (\%) & MI+Tivortin (\%) \\
\hline ATP $(\mu \mathrm{mol} / \mathrm{g})$ & $2.91 \pm 0.18$ & $1.62 \pm 0.12(-44.3)$ & $1.71 \pm 0.16(+5.5)$ \\
Malate $(\mu \mathrm{mol} / \mathrm{g})$ & $0.67 \pm 0.02$ & $0.19 \pm 0.02(-71.6)$ & $0.21 \pm 0.07(+10)$ \\
Lactate $(\mu \mathrm{mol} / \mathrm{g})$ & $2.11 \pm 0.18$ & $7.57 \pm 0.53(+258.7)$ & $7.80 \pm 0.78(+3)$ \\
MDG $(\mu \mathrm{M} / \mathrm{mg} / \mathrm{minute})$ & $6.88 \pm 0.11$ & $3.10 \pm 0.1(-55)$ & $4.17 \pm 0.1(+34)$ \\
\hline
\end{tabular}

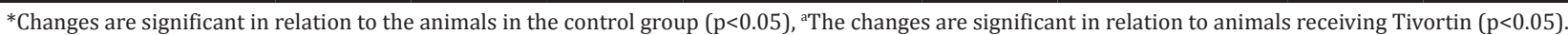

MI: Myocardial infarction, MDG: Malate dehydrogenase

Table 2: Indicators of the NO system and renewed thiols in the cytosolic fraction of the heart of animals

\begin{tabular}{llll}
\hline Studied indicators & Intact & MI (control) (\%) & MI+Tivortin (\%) \\
\hline Renewed thiols $(\mu \mathrm{mol} / \mathrm{g})$ & $185.1 \pm 11.7$ & $92.1 \pm 6.1(-50.2)$ & $115.0 \pm 10.5^{*}(+25)$ \\
GR $(\mu \mathrm{M} / \mathrm{mg} / \mathrm{minute})$ & $18.7 \pm 0.71$ & $9.6 \pm 0.31(-48.6)$ & $12.2 \pm 0.11^{*}(+27)$ \\
NO synthase $(\mu \mathrm{mol} / \mathrm{mg} / \mathrm{minute})$ & $37.2 \pm 3.2$ & $17.5 \pm 1.5(-53)$ & $26.8 \pm 1.3^{*}(+53)$ \\
Stable metabolite of NO $(\mu \mathrm{mol} / \mathrm{g})$ & $25.1 \pm 2.7$ & $9.3 \pm 0.78(-63)$ & $19.1 \pm 1.8^{*}(+105)$ \\
Nitrotyrosine $(\mathrm{nmol} / \mathrm{g})$ & $66.5 \pm 6.7$ & $493.3 \pm 18.2(+641.8)$ & $28.3 \pm 1.11^{*, a}(121.8)$ \\
\hline
\end{tabular}

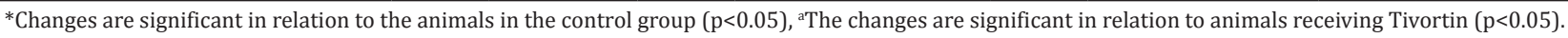

GR: Glutathione reductase, NO: Nitric oxide, MI: Myocardial infarction

Table 3: Indicators of oxidative stress and antioxidant system in the cytosolic fraction of the heart of animals

\begin{tabular}{llll}
\hline Studied indicators & Intact & MI (control) (\%) & MI + Tivortin (\%) \\
\hline Catalase $(\mathrm{MAb} / \mathrm{mg})$ & $17.2 \pm 1.5$ & $8.70 \pm 0.77(-50)$ & $10.5 \pm 0.71(+20.6)$ \\
PGR $(\mu \mathrm{mol} / \mathrm{mg} / \mathrm{minute})$ & $154.2 \pm 11.2$ & $73.7 \pm 6.83(-52.2)$ & $80.4 \pm 7.55(+9)$ \\
AFG (c.u./g) & $10.2 \pm 1.21$ & $35.7 \pm 2.11(+250)$ & $29.7 \pm 2.16^{*}(-16.8)$ \\
CCF (c.u./g) & $6.52 \pm 0.71$ & $19.7 \pm 1.71(+202)$ & $17.3 \pm 1.33^{*, a}(+110)$ \\
\hline
\end{tabular}

${ }^{*}$ The changes are significant in relation to the animals of the control group $(\mathrm{p}<0.05)$, ${ }^{\mathrm{a}}$ The changes are significant in relation to animals receiving Tivortin $(\mathrm{p}<0.05)$.

AFG: Aldehyde phenylhydrazone, PGR: Progesterone receptor, MI: Myocardial infarction

of NO and has a protective effect on NO transfer in ischemia, due to the preservation of renewed thiols. This action is very important in the acute period of myocardial ischemia and plays a paramount role in the realization of the cardioprotective effect of these drugs. Argitryl was more effective in terms of impact on the indicators of conjugated NO system/renewed thiols. Thus, the designed combined "Argitryl" provides double protection against the NO system under conditions of ischemia. Thus, the first component of Argitryl, L-arginine, increases the production of NO, and the second component, thiotriazolin, increases the bioavailability of $\mathrm{NO}$, due to the formation of stable S-nitrosyl complexes, thereby maintaining the physiological and cardioprotective properties of this molecular transmitter. The analysis of the obtained data in Table 3 shows that the modeling of myocardial infarction leads to the development of oxidative stress.

Hence, the increase of oxidative modification of protein products - AFG in 3.5 times and CCF in 3 times on the background of suppression of activity of antioxidant enzymes - HPR by $52.2 \%$ and catalase by $50 \%$ compared with those of intact groups were registered in myocardium from animals of the control group. The administration of Tivortin and Argitryl to animals with MI has significant antioxidant effect - the significant reduction in oxidative stress markers (AFG [by 6.8\%, 54\%] and CCF [by 13\%, 38.5\%]) in the myocardium. The significant increase of antioxidant enzyme activity - catalase by $110 \%$ and PGR by $119 \%$ was found in the myocardium of animals which have been treated with Argitryl. It makes antioxidant effect of Argitryl more pronounced in comparison with similar effect of Tivortin.

As a result of studies, we found the presence of the antioxidant and energotropic NO-modulating mechanisms of cardioprotective and anti-ischemic actions of Argitryl and Tivortin on the myocardial infarction model. The stopping of reactions of oxidative stress (AFG reduction by $54 \%, 16.8 \%$ and $\mathrm{CCF}$ reduction by $38.5 \%, 13 \%$ on the background of the increase of catalase activity by $110 \%, 20.6 \%$ and HPR by $119 \%, 9 \%$ ) compared to the control group was registered as a result of administration of Argitryl and Tivortin to animals with pituitrin-izadrine myocardial infarction. It has been found that the administration of Argitryl and Tivortin to animals with myocardial infarction had a positive effect on the energy metabolism of ischemic myocardium - increase of ATP $(70 \%, 5.5 \%)$, malate $(384 \%, 10 \%)$, and MDG $(118 \%, 34 \%)$ on the background of lower lactate compared with the control group. The administration of Argitryl and Tivortin to experimental animals with myocardial infarction resulted in normalization of the NO conjugate system/renewed thiols - increased NOS activity $(65 \%, 53 \%)$, increased stable NO metabolites $(159 \%$, $105 \%)$, renewed thiols $(86.4 \%, 25 \%)$, and reduced nitrotyrosine $(81 \%$, $35 \%$ ). Argitryl is significantly superior Tivortin on the effect on the studied indicators of antioxidant and energotropic NO-modulating mechanisms of cardioprotective and anti-ischemic action.

\section{CONCLUSION}

The results are experimental confirmation for creating drug with cardioprotective, anti-ischemic properties based on fixed combination of thiotriazolin and L-arginine (Argitryl).

\section{REFERENCES}

1. Mazur I, Chekman I, Belenichev I. Metabolithotropic Drugs. Ukraine: Zaporozhye; 2007

2. Vurumadla S, Rakshith V, Murari $\mathrm{CH}$, Venkateshwarlu K. A study on symptoms, risk factors and prescribing pattern of drugs used in stroke patients. Int J Pharm Pharm Sci 2015;7(1):421-26.

3. Lass A, Suessenbacher A, Wölkart G, Mayer B, Brunner F. Functional and analytical evidence for scavenging of oxygen radicals by L-arginine. Mol Pharmacol 2002;61:1081-8.

4. Vizir V, Voloshin N, Mazur I, Belenichev I. Metabolic Cardioprotectors. Ukraine: Zaporozhye; 2006.

5. Mazur I, Chekman I, Belenichev I, Kucherenko L, Horchakova N, Bukhtiyarova $\mathrm{N}$, et al. The development of drugs based on fixed combinations with antioxidants is a promising area of modern pharmacology. Fharmacol Drug Toxicol 2011;5:199-200.

6. Mazur I, Kucherenko L, Belenichev I, Khomylova O, Syusyuka V. Owner SPA "Farmatron". Combination Drug with Hepatoprotective, Cardioprotective, Placentoprotective, Tocolytic and NO-Mimetic 
Action/- No. a 201506388. Ukraine: IPC; (2015.01) A61K 31/198 (2006.01), A61K 9/00; appl. 30.06.2015; publ. 12.01.16. Bul. № 1 Invention patent 110597.

7. Nahornaya E. Preclinical Safety Studies as the Basis for Clinical Trials Involving Human and Registration of Drugs (ICHM3(R2)). Ukraine: Kiev, DEC Ministry of Healthcare; 2014.

8. Kozhemyakyn Y, Khromov O, Phylonenko M, Sayfetdynova H. Scientific Guidelines for Keeping Laboratory Animals and Working with Them. Ukraine: Kiev, Avitsena; 2002

9. Voronina T, Seredinin S. Manual on Experimental (Preclinical) Study of New Pharmacological Substances. Russia: Remedium; 2002.

10. Stefanov A, Стефанов AB. Preclinical Studies of Medicines. Ukraine: Kiev, Avitsena; 2002.

11. Aruoma O, Halliwell B. Molecular Biology of Free Radicals in Human Diseases. St. Lucia, London: OCIA Int.; 1999. p. 345.

12. Prokhorova M. Modern Methods in Biochemistry. Russia: LSU; 1986.

13. Mishra A, Keshari AK, Singh AK, Maity S, Nandy B, Saha S. Oxidative stress-based hepatotoxicity of duloxetine in Wistar rats. Int J Pharm Pharm Sci 2016;8(11):28-32. 